\title{
West Germany boosts research by one fifth
}

Germany is playing for a big lead in innovation, writes Robert Walgate from Bonn

Almost without debate, the Bundestag last month increased the budget of the West German Ministry for Research and Technology (BMFT) by $19.8 \%$ to DM5.5 billion. The emphasis is on stimulating innovation, not basic science. For example, the Deutsche Forschungsgemeinschaft (DFG), responsible for basic research in the universities, received only a $4 \%$ increase. But the ministry's programme for stimulating innovation jumped $129 \%$.

There were also big increases in many of the directed programmes of the BMFT, particularly in electronics $(32 \%)$, transport $(58 \%)$, and energy, which rises $21 \%$ from DM1,720 million in 1978 to DM2,080 million in 1979. The non-nuclear research programme is growing particularly fast. It will reach DM533 million in 1979, 52\% above its cost in 1978 .

The increase in the transport budget represents confidence in the Erlangen Research Centre in Bavaria, where the government has already invested DM250 million in the Siemens, AEG, and Brown Boveri $450 \mathrm{~km} / \mathrm{h}$ hovertrain. The investment in electronics will stimulate research in microprocessor technology.

The BMFT was not the only ministry to increase its research budget: the Ministry for Industry also announced a DM300 million boost for research in small and medium sized firms, to cover up to $30 \%$ of the cost of employing new research staff. It is hoped that this will not only correct the imbalance whereby some $90 \%$ of government-supported industrial research has been allocated to only 40 firms, but might also provide employment for the 50,000 or so un- or underemployed scientists in Germany.

Germany may be in a position of great economic strength at present, but it is certainly taking very seriously the challenges provided by its lack of natural resources, and the increasing industrial competition from Third World countries with their low labour costs. Germany seems determined to invest effectively in its brains. However there may be a more immediate reason for the success of the BMFT in this budget. The previous minister, Hans Matthoefer, is now Finance Minister in overall control of the budget, so Volker Hauff, the 38-yearold economist who now runs BMFT, has had a sympathetic ear.

However, the Bundestag itself showed little interest in the developments. Despite a two-day debate (23-24 January) on the whole German Budget, only the last 90 minutes (from 10.30 pm to midnight) were devoted to the affairs of the BMFT. A leading commentator on science politics in West Germany, Hartmut Altenmueller, wrote: "The interest that politicians and the public take in science was shown by the debate in the Bundestag last week. Zero." Only one parliamentarian, says Altenmueller, criticised the situation. This was Herr Laermann of the Centre Party, FDP (which has been taking an interest in ecology and the Kalkar fast breeder reactor lately). Laermann argued that it was time the Bundestag took an interest in the politics of science and technology before the government had formed its policy, made its mistakes, and presented the Bundestag with a fait

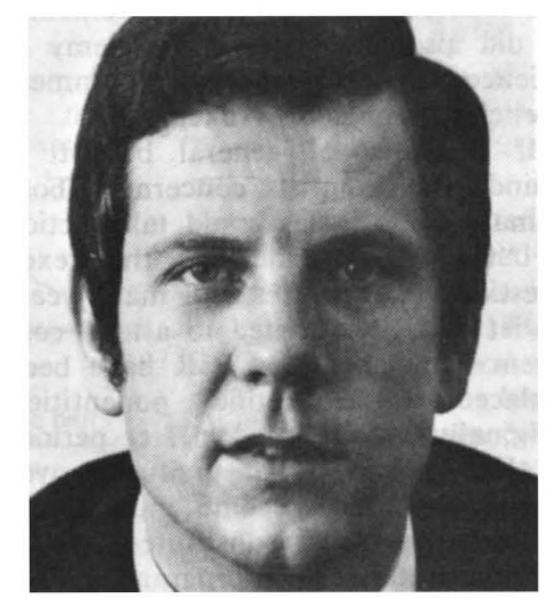

Technology minister Volker Hauff

accompli. But little attention was paid to his speech.

On a longer perspective, however, German science politics is becoming increasingly interesting, and it would seem impossible that the Bundestag could ignore the issues. For example, Professor Helmar Krupp, Director of the Institut für Systemtechnik und Innovationsforschung (ISI), believes that there is a growing awareness in Germany that technology must be looked at through the eyes of labour: what is it like to work with technology, what influence does it have on life? Moreover, this concern, he feels, is not the exclusive property of the ruling SPD coalition. "The awareness is greater here in Germany that we must rely on high technology, that intensive work with raw materials will go out".

The government is increasingly turning to institutes like his own (it is similar to the Science Policy Research Unit at the University of Sussex in the
UK) to ask for expert advice in matters of science and technology policy. For example, the DM300 million programme for stimulation of research in small and medium sized industry was designed within ISI in close cooperation with the ministry.

The energy issues, says Krupp, are much the same in Germany as elsewhere. But in basic science, Germany is facing some interesting questions. The Max Planck Institute for Plasma Physics in Garching, near Munich, is recovering rapidly from the blow of losing the joint European Tokamak (JET) project to Culham in the UK. It is now forming a proposal for a device not dissimilar in price to JET itself

JET was delayed for some years by Brussels politics, and in some respects its design is dated. The Garching project, costing DM280 million, would be designed specifically to achieve nuclear ignition in the plasma, whereas JET is primarily a device to test scale-up (though it may also achieve ignition). The Garching device would be designed to take account of the radiation hazards.

The proposal is not yet finalised even within Garching, because one of the divisions (high beta plasmas) would have to close. But it is the main contender for Garching's main programme after ASDEX (a device under construction to test the concept of a 'divertor' to clean impurities from the edge of the plasma column). The ignition device would probably be a collaboration between Garching and MIT in the US. The view of the BMFT is not known, but, says a physicist at Garching, "at least they haven't stopped the study"

Another issue which seems sure to come to a head soon lies in a conflict between the basic research funding body DFG and the ministries concerned with a govermment special programme on 'health research'. Officials at the DFG are: worried that criteria used for selecting research for funding under the independent, DM450 million five-year health research programme are too lax. "There is a problem of inflation of pcor projects", said one DFG official. "Projects are defined loosely, and so are the assessments". Furthermore the ministries reserve the right to ignore the advice of the scientists they appoint to do the assessments, so that poor research can be funded purely on political grounds.

More recently the DFG has been asked to set up a committee to advise the government on cancer research. It may well be in that committee that the issue will be raised. 